\title{
Synthesis of Polymer Microspheres with Mercapto Groups by Polycondensation of 1,3-Propanedithiol and 1,6-Dibromohexane in the Presence of a Poly[styrene-alkylacrylamide] Latex
}

\author{
Shinji Watanabe ${ }^{\dagger}$, Ryo Ikeda, Hiroaki Ikeda, Miki Murata, and Yuzuru Masuda \\ Department of Materials Science, Kitami Institute of Technology, Kitami, Hokkaido 090-8507, Japan
}

(Received August 11, 2003; Accepted October 22, 2003)

\begin{abstract}
Polymer microspheres with mercapto groups were synthesized by the polycondensation of 1,3-propanedithiol and 1,6-dibromohexane in the presence of a poly[styrene (S)-alkylacrylamide (RAM)] latices. Monodisperse microspheres were obtained in quantitative yields by using seed particles with hydrophilic surface [PS- $N$ (hydroxymethyl)acrylamide (HMAM), PS-acrylamide (AM), PS-methacrylamide (MAM), and PS- $N, N$-dimethylacrylamide (DMAM)]. While using seed particles with hydrophobic surface [PS- $N$-isopropylacrylamide (NIPAM)], all of the polymer was coagulated and no polymer particles were obtained after the polycondensation. The particles prepared with large excess dithiol monomers had high mercapto group contents. The distribution of mercapto group on the particle was estimated by Ellman method using both $N, N$-dimethylformamide (DMF) and a mixture of ethanol and water as solvents, indicating that most of mercapto groups were localized on the surface, in the particles with high mercapto group contents. In methanol, the mercapto groups near the surface were preferentially oxidized with iodine, while in KI aq. solution, the internal mercapto groups of particles were mainly oxidized.

KEY WORDS Polymer Microsphere / Mercapto Groups / Seed Polymerization / Polycondensation /
\end{abstract}

Polymer microspheres with well-characterized surface were utilized with a variety of applications such as coatings, paints, adhesives, polymer catalyst, immobilized enzyme, and diagnostic tests. So far various functional groups, amine, ${ }^{1}$ carboxylic acid, ${ }^{2}$ benzyl chloride, ${ }^{3}$ and epoxide ${ }^{4}$ were introduced into the polymer microsphere. One of the other functional groups is a mercapto group, which has specific reactivities such as strong nucleophilicity, radical captured property, strong binding with noble metal ions, and easy formation of some oxidized products depending on the specific reaction conditions. ${ }^{5}$ There were a few applications using polymer microsphere having mercapto groups, such as immobilization of Fab antibody fragments ${ }^{6}$ and preparation of the MMA-grafted polymer particles via the radical transfer to mercapto group in the radical polymerization of MMA. ${ }^{7}$

However, it is difficult to directly introduce mercapto group into polymer microsphere because of its high radical chain transfer activity. Thus, the microspheres having mercapto groups have been prepared by the two preparation steps, i.e., the introduction of functional groups such as isothiuronium salts ${ }^{8,9}$ epoxides, ${ }^{4 a}$ or thioacetates ${ }^{7}$ into polymer particles, and their subsequent conversion to mercapto group on the polymer surface. Recently, we reported a novel method for preparing polymer microspheres having mercapto groups, by means of the polycondensation of $\alpha, \omega$-alkanedithiol and $\alpha, \omega$-dibromoalkane in the presence of PS latex ${ }^{10,11}$ or P(S-HMAM) latex. ${ }^{12}$ The condensation reaction proceeded in the polymer particles and the end groups of polysulfide, i.e., mercapto groups, were immobilized directly onto the polymer particle. The particle stability in the course of the polycondensation significantly depended on the seed particles. When PS latex was used in the polycondensation, particles with broad size distribution were formed, even if nonionic surfactant as a stabilizer was used. ${ }^{10,11}$ While by using P(S-HMAM) as seed particles, monodisperse microspheres bearing mercapto groups were obtained after the polycondensation in quantitative yield. ${ }^{12}$ Hydrophilic hydroxymethylamide groups stabilized the particles during the polycondensation. In this paper, some P(S-RAM) latices with various hydrophilic surfaces were utilized as seed particles for the polycondensation of 1,3-propanedithiol with 1,6-dibromohexane, and the dispersion stability and the mercapto group content of particles were studied in the view of surface hydrophilicity.

\section{EXPERIMENTAL}

\section{Measurement}

The diameters of polymer microspheres were determined by a scanning electron microscope (JEOL JSM588 scanning microscope). The molecular weight of

${ }^{\dagger}$ To whom correspondence should be addressed (E-mail: watash@mail.kitami-it.ac.jp). 
polymer was determined by size-exclusion chromatography (SEC) measurement on a TOSOH HLC 8020 instrument equipped with a refractive index detector using tetrahydrofuran (THF) as an eluent at $40^{\circ} \mathrm{C}$. Because the P(S-HMAM) particles were not completely soluble in THF, the soluble polymer was extracted with chloroform using a Soxhlet extractor for $5 \mathrm{~h}$. The polymers prepared from the other seed particles were directly measured by the SEC instrument.

\section{Materials}

All reagents were obtained commercially and used as received. $\mathrm{P}(\mathrm{S}$-alkyl acrylamide) latices $\mathrm{P}(\mathrm{S}-\mathrm{RAM})$ were prepared by the reported method. ${ }^{13}$

\section{Polycondensations}

Into a $100-\mathrm{mL}$ flask equipped with a condenser, 1,6-dibromohexane $(0.488 \mathrm{~g} ; 2.00 \mathrm{mmol})$ and $\mathrm{P}(\mathrm{S}-\mathrm{RAM})$ latex $(1.0 \mathrm{~g})$ dispersed in deionized water $(30 \mathrm{~mL})$ were placed and stirred for $30 \mathrm{~min}$ at room temperature. Into the mixture, 1,3-propanedithiol $(0.271 \mathrm{~g} ; 2.50 \mathrm{mmol})$ in $1.0 \mathrm{M}$ potassium hydroxide aqueous solution $(5.0 \mathrm{~mL} ; 5.0 \mathrm{mmol})$ was added. The reaction mixture was purged with nitrogen and the temperature was raise to $100^{\circ} \mathrm{C}$. The polycondensation was carried out at $100^{\circ} \mathrm{C}$ for $24 \mathrm{~h}$ in nitrogen atmosphere. After cooling, the coagulated polymer was removed by filtration and the microsphere was centrifuged with deionized water for three times $(18500 \mathrm{~g})$.

\section{Mercapto Group Content of the Polymer Micro- spheres}

The mercapto group content of the microspheres was determined by Ellman method using either ethanol-water mixture (vol. ratio $1 / 1)^{8}$ or dimethylformamide (DMF) solvent ${ }^{14}$ following to the literature methods.
Oxidation of Mercapto Group on the Polymer Particles with Iodine in Methanol

Into the flask, $0.18 \mathrm{~g}$ (SH content: $50 \mu \mathrm{mol}$ ) of polymer microsphere (run no. 1; see Table II) was suspended in $20 \mathrm{~mL}$ of methanol followed by addition of $3.2 \mathrm{mg}(12.5 \mu \mathrm{mol})$ of iodine in methanol $(10 \mathrm{~mL})$. The mixture was stirred at room temperature for $24 \mathrm{~h}$. The particles were purified by centrifugation with methanol for three times $(18500 \mathrm{~g})$. The mercapto group content and the molecular weight of particles were measured.

\section{RESULTS AND DISCUSSION}

\section{Preparation of $P(S-R A M)$ Latices as Seed Particles}

Five kinds of $\mathrm{P}(\mathrm{S}-\mathrm{RAM})$ latices with various hydrophilic surfaces were prepared by soap-free emulsion polymerization of S copolymerized with RAM following the literature method. ${ }^{13}$ As shown in Table I, all latices with narrow size distribution were obtained quantitatively.

Since the hydrophilicity of amide monomer affected the latices stability in water, the order of seed particles stability should be $\mathrm{P}(\mathrm{S}-\mathrm{HMAM}), \mathrm{P}(\mathrm{S}-\mathrm{AM})$, $\mathrm{P}(\mathrm{S}-\mathrm{MAM}), \mathrm{P}(\mathrm{S}-\mathrm{DMAM})$, and P(S-NIPAM).

Table I. Preparation of P(S-RAM) latices as seed particles ${ }^{\mathrm{a}}$

\begin{tabular}{|c|c|c|c|}
\hline \multirow[t]{2}{*}{ Seed } & $S$ & RAM & Diameter \\
\hline & $\mathrm{g}$ & $\mathrm{g}$ & $\mu \mathrm{m}$ \\
\hline $\mathrm{H}$ & 8.5 & HMAM: 1.5 & $0.264 \pm 0.010$ \\
\hline A & 8.5 & AM: 1.5 & $0.245 \pm 0.024$ \\
\hline M & 8.5 & MAM: 1.5 & $0.243 \pm 0.022$ \\
\hline $\mathrm{D}$ & 7.0 & DMAM: 3.0 & $0.359 \pm 0.009$ \\
\hline I & 8.5 & NIPAM: 1.5 & $0.498 \pm 0.053$ \\
\hline
\end{tabular}

${ }^{\mathrm{a}} 0.01 \mathrm{M}$ Carbonate buffer (pH 10.50) $160 \mathrm{~mL}, \mathrm{~K}_{2} \mathrm{~S}_{2} \mathrm{O}_{8}$ : $0.529 \mathrm{mmol}$, condition: $70^{\circ} \mathrm{C} 20 \mathrm{~h}$.

Table II. Polycondensation of propanedithiol and dibromohexane in the presence of P(S-RMA) latex ${ }^{\mathrm{a}}$

\begin{tabular}{|c|c|c|c|c|c|c|c|}
\hline \multirow[t]{2}{*}{ Run No. } & \multirow[t]{2}{*}{ Seed } & \multirow{2}{*}{$\begin{array}{c}\text { Propanedithiol } \\
\text { mmol }\end{array}$} & \multirow{2}{*}{$\begin{array}{c}\text { Yield } \\
\%\end{array}$} & \multirow{2}{*}{$\begin{array}{c}\text { Diameter } \\
\mu \mathrm{m}\end{array}$} & \multicolumn{2}{|c|}{ SH content $(\mu \mathrm{mol} / \mathrm{g})$} & \multirow[t]{2}{*}{$\mathrm{Mn}^{\mathrm{b}}$} \\
\hline & & & & & Surface $^{c}$ & $\mathrm{All}^{\mathrm{d}}$ & \\
\hline 1 & $\mathrm{H}$ & 2.5 & 98 & $0.306 \pm 0.014$ & 168 & 274 & 1837 \\
\hline 2 & $\mathrm{H}$ & 3.0 & 90 & $0.307 \pm 0.018$ & 701 & 703 & 1410 \\
\hline 3 & A & 2.5 & 95 & $0.293 \pm 0.030$ & 226 & 344 & 1530 \\
\hline 4 & A & 3.0 & 98 & $0.306 \pm 0.027$ & 647 & 694 & 1520 \\
\hline 5 & M & 2.5 & 93 & $0.304 \pm 0.028$ & 227 & 360 & 1190 \\
\hline 6 & M & 3.0 & 95 & $0.318 \pm 0.021$ & 502 & 536 & 1350 \\
\hline 7 & $\mathrm{D}$ & 2.5 & 96 & $0.403 \pm 0.013$ & 51 & 133 & 4820 \\
\hline 8 & $\mathrm{D}$ & 3.0 & 71 & $0.398 \pm 0.013$ & 314 & 390 & 3310 \\
\hline 9 & I & 2.5 & $0^{\mathrm{e}}$ & - & - & - & - \\
\hline
\end{tabular}

${ }^{a}$ Seed particles (see Table I): $1.0 \mathrm{~g}$, Dibromohexane: $2.0 \mathrm{mmol}$, KOH: $5.0 \mathrm{mmol}, \mathrm{H}_{2} \mathrm{O}: 35 \mathrm{~mL}$; condition: $100{ }^{\circ} \mathrm{C}$ $24 \mathrm{~h} .{ }^{\mathrm{b}}$ Number average molecular weight of polysulfide determined by SEC calibrated with polystyrene standard in THF. ${ }^{\mathrm{c}} \mathrm{SH}$ content of polymer microsphere determined by Ellman method in a mixture of ethanol and water $(\mathrm{v} / \mathrm{v}=1 / 1) .{ }^{\mathrm{d}} \mathrm{SH}$ content of polymer microsphere determined by Ellman method in DMF. ${ }^{\mathrm{e}}$ All of polymer was coagulated during the polycondensation. 
Polycondensation of 1,6-Dibromohexane and 1,3Propanedithiol in the Presence of P(S-RAM) Latices

The microspheres having mercapto groups were prepared by the polycondensation of 1,6-dibromohexane and 1,3-propanedithiol in the presence of polymer latices as seed particles.

The polymer particles were destabilized during the polycondensation because of the addition of electrolyte, $\mathrm{KOH}$. On the use of PS latices as seed particles, it was necessary to use a nonionic surfactant, triton ${ }^{\circledR}$ $\mathrm{X}-405$ and to elevate polymerization temperature gradually (at $60^{\circ} \mathrm{C}$ for $2 \mathrm{~h}$, at $80^{\circ} \mathrm{C}$ for $2 \mathrm{~h}$, and at $100^{\circ} \mathrm{C}$ for $20 \mathrm{~h}$ ) to obtain particles with mercapto groups. When the polycondensation was conducted without a nonionic surfactant or the temperature was elevated to $100^{\circ} \mathrm{C}$ at once, all polymer was coagulated in the initial stage of the polycondensation. ${ }^{10,11} \mathrm{Al}$ though the surfactant played a predominant role in the particles stability, its presence might provide some drawbacks due to the dynamic equilibrium with water phase: for instance, desorption during the polycondensation to form the secondary particles or migration during the film formation, then causing drastic increase in the water sensitivity and permeability. Thus we tried to carry out the polycondensation without a surfactant using the seed particles with hydrophilic surface.

Polycondensations of 1,3-propanedithiol and 1,6dibromohexane were performed in the presence of P(S-RAM) latices instead of PS latex as seed particles. The results are listed in Table II. The polymer microspheres with the mercapto groups were obtained quantitatively using $\mathrm{P}(\mathrm{S}-\mathrm{RAM})$ seed particles except $\mathrm{P}(\mathrm{S}-\mathrm{NIPAM})$ (Seed I), even though the polymerization was carried out in the absence of nonionic surfactant and the temperature was raised to $100^{\circ} \mathrm{C}$ at once. The diameters of particles after polycondensations were a little larger than the corresponding seed ones and no secondary particles were found to be formed, which indicated that the polycondensation proceeded in the seed particles. Although a high concentration of electrolyte $(\mathrm{KOH})$ existed in the aqueous media, the hydrophilic amide moiety enhanced the particle stability to afford monodisperse microspheres in quantitative yields.
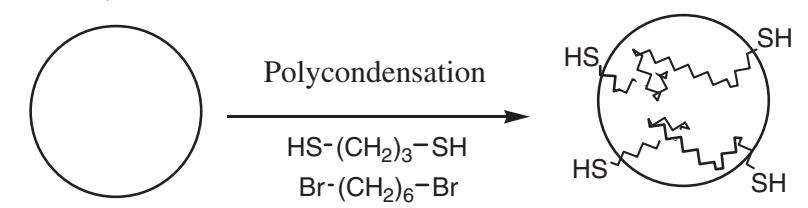

P(S-RAM) Latex

On the other hand, in the case of P(S-NIPAM) particles (Seed I), all polymer was coagulated in the course of polycondensation. The isopropylamide groups were not enough hydrophilic to stabilize the particles in the polycondensation. P(NIPAM) has a cloud point at around $32^{\circ} \mathrm{C}$, and above this temperature in water, the polymer precipitates due to the loss of coordinated water. Since the P(NIPAM) on particles might be stabilized at low temperature, the polycondensation was conducted in the gradual elevated temperature i.e., at $30^{\circ} \mathrm{C}$ for $1 \mathrm{~h}$, at $40^{\circ} \mathrm{C}$ for $1 \mathrm{~h}$, at $50^{\circ} \mathrm{C}$ for $1 \mathrm{~h}$, and at $60^{\circ} \mathrm{C}$ for $21 \mathrm{~h}$. Although parts of polymer particles were obtained in this condition, most of polymer particles were found to be fused together by SEM observation.

\section{Mercapto Group Content of Particles and Molecular Weight of Polysulfide}

The mercapto group contents of particles were measured by Ellman method using both ethanol-water mixture (v/v = 1/1) and DMF as solvents. In ethanol-water mixture, only mercapto groups near the surface were detected, because the Ellman reagent (5,5'dithiobis-(2-nitrobenzoic) acid) could not reach the inside of particle due to the poor solubility of the polymer. While, since the polymers were soluble or highly swelled in DMF, all mercapto groups were detectable. ${ }^{12}$ The mercapto group contents of particles are summarized in Table II. When any seed particles were used in the polycondensation, particles prepared with a large excess of dithiol $(3.0 \mathrm{mmol})$ had high mercapto group content. Furthermore mercapto group contents measured in ethanol-water mixture were almost same as those in DMF, indicating that most of mercapto groups existed near the surface. While, the mercapto group contents of particles prepared with $2.5 \mathrm{mmol}$ of propanedithiol, measured in DMF were much larger than those in ethanol-water mixture. Considerable amount of mercapto group was buried inside the particles.

Figure 1 illustrates the SEC charts of the seed particles (seed A; see Table I) and the microsphere prepared with seed A (run no. 4; see Table II). In the seed polymer, a high molecular weight fraction (5.2-7.8 elusion count) and a small low molecular weight peak existed. After the polycondensation, the low molecular weight peak appeared at about 8-10 elusion count, which should be derived from polysulfide. The approximate molecular weights of polysulfide were estimated from the low molecular weight fraction and listed in Table II.

Interestingly, the molecular weights of polysulfides were not appreciably dependent on the amount of dithiol monomer. This indicated that all of the end groups were not mercapto groups especially where $2.5 \mathrm{mmol}$ of propanedithiol was used. For example, when the molecular weights of the polysulfide were 1520 (run no. 3 and 4), the mercapto group contents were about $505 \mu \mathrm{mol} / \mathrm{g}$ based on the assumption that 
all of the end groups were mercapto groups. Almost all end groups of polysulfide (run no. 4) must be mercapto groups because their content determined in DMF $(694 \mu \mathrm{mol} / \mathrm{g})$ was higher than the calculated one, while, some end groups of polysulfide made from $2.5 \mathrm{mmol}$ of dithiol (run no. 3) were bromo groups be- cause of a smaller amount of mercapto group content $(344 \mu \mathrm{mol} / \mathrm{g})$. And that the molecular weights of polysulfides from $\mathrm{P}(\mathrm{S}-\mathrm{DMAM})$ particles were highest in the all particles. This leaded to lower the end group i.e., mercapto group content.

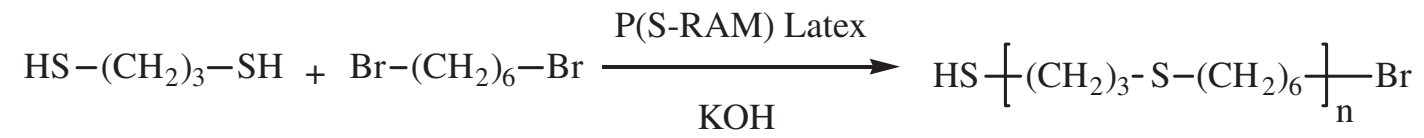

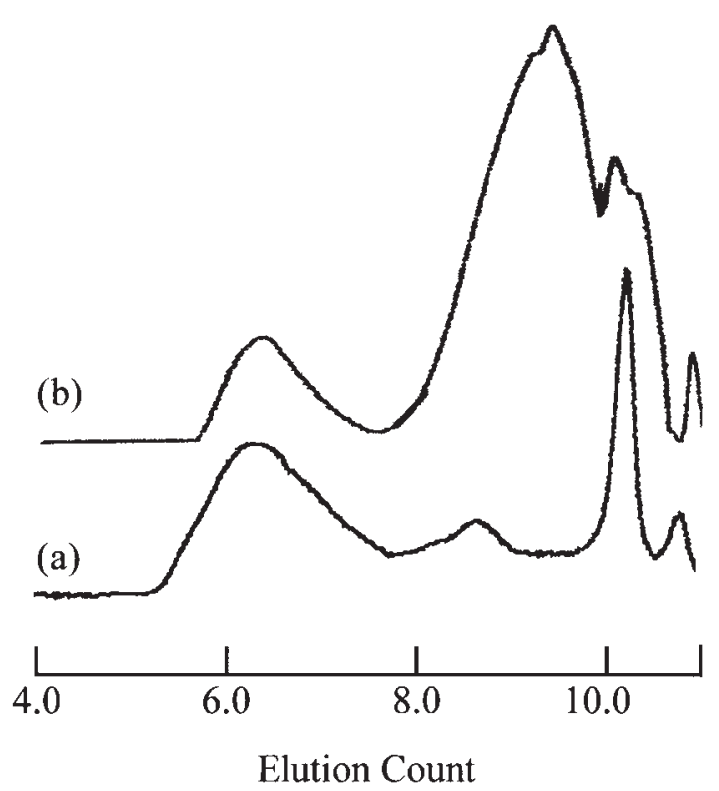

Figure 1. SEC elusion curves of Seed A (a), and polymer microsphere with mercapto groups, run no. 4 (b).

This polycondensation was a kind of interfacial polycondensation. ${ }^{15}$ Dithiol and potassium hydroxide formed potassium mercaptide to exist in an aqueous medium, while hydrophobic dibromohexane was in the polymer particles. The mercaptide entered polymer particles and then reacted with dibromide. An excess of dithiol $(3.0 \mathrm{mmol})$ against dibromide could enter the particle easily and react with the bromide monomer near the surface yielding the particles with high SH content. As the condensation proceeded, the bromide near the surface was consumed and the internal dibromide was diffused to the surface. Consequently most of polysulfides (and also mercapto groups) were localized near the surface. While, when a little excess of dithiol $(2.5 \mathrm{mmol})$ was used in the polycondensation, the condensation reaction did not proceeded smoothly, and some polysulfide chains might be diffused into the particle inside, leading that the significant amount of SH groups buried into the particles.

The mercapto group contents in hydrophilic parti- cles (P(S-HMAM), $\mathrm{P}(\mathrm{S}-\mathrm{AM})$, or $\mathrm{P}(\mathrm{S}-\mathrm{MAM})$ ) were higher than that from the $\mathrm{P}(\mathrm{S}-\mathrm{DMAM})$ particles (seed D). In the previous paper, the small P(S-HMAM) used as seed particles tended to afford the particles having high mercapto group content because of their large interface area. ${ }^{11}$ The $\mathrm{P}(\mathrm{S}-\mathrm{DMAM})$ particles were the largest in the seed particles, this might lead to the particles having small mercapto group content.

\section{Oxidation of Mercapto Group on the Polymer Parti- cles with Iodine}

Mercapto group was known to be oxidized to disulfide with iodine. ${ }^{16}$ The oxidation of mercapto groups in the particles was carried out in either methanol or KI $a q$. solution as shown in Table III. Half equivalents of iodine to the mercapto group were used in the reaction. After the oxidation, mercapto group contents decreased. Furthermore the molecular weight of polysulfide increased, because the oxidization of mercapto groups formed disulfides.

$$
\mathrm{R}^{1}-\mathrm{SH}+\mathrm{HS}-\mathrm{R}^{2} \stackrel{\mathrm{I}_{2}}{\longrightarrow} \mathrm{R}^{1}-\mathrm{S}-\mathrm{S}-\mathrm{R}^{2}+2 \mathrm{H}-\mathrm{I}
$$

Table III. Oxidation of mercapto group in microsphere

\begin{tabular}{|c|c|c|c|}
\hline & \multicolumn{2}{|c|}{ SH content $(\mu \mathrm{mol} / \mathrm{g})$} & \multirow[t]{2}{*}{$\mathrm{Mn}^{\mathrm{b}}$} \\
\hline & Surface ${ }^{c}$ & $\mathrm{All}^{\mathrm{d}}$ & \\
\hline Run no. 1 & 168 & 274 & 1840 \\
\hline Oxidized in KI $a q$. & 108 & 127 & 5750 \\
\hline Oxidized in methanol & 87 & 174 & 6200 \\
\hline Run no. 3 & 226 & 344 & 1530 \\
\hline Oxidized in KI $a q$. & 77 & 93 & 8410 \\
\hline Oxidized in methanol & 77 & 202 & 2340 \\
\hline Run no. 5 & 227 & 360 & 1190 \\
\hline Oxidized in KI $a q$. & 201 & 247 & 1850 \\
\hline Oxidized in methanol & 83 & 212 & 1685 \\
\hline
\end{tabular}
with iodine ${ }^{\mathrm{a}}$

${ }^{a}$ Mercapto groups of microsphere: $50 \mu \mathrm{mol}, \mathrm{I}_{2}: 12.5 \mu \mathrm{mol}$, solvent $10 \mathrm{~mL}$; condition: at room temperature for $24 \mathrm{~h}$. ${ }^{b}$ Number average molecular weight of polysulfide determined by SEC calibrated with polystyrene standard in THF. ${ }^{\mathrm{S}} \mathrm{SH}$ content of polymer microsphere determined by Ellman method in a mixture of ethanol and water $(\mathrm{v} / \mathrm{v}=1 / 1) .{ }^{\mathrm{d}} \mathrm{SH}$ content of polymer microsphere determined by Ellman method in DMF. 
In methanol solution, the mercapto group near the surface was oxidized preferentially. On the other hand, the internal mercapto group was mainly oxidized in KI $a q$. solution. Since iodine was highly soluble in methanol, the mercapto groups near the surface were oxidized. While in KI aq. solution, most of iodine existed in the particles and oxidized preferentially the internal mercapto groups.

In conclusion, we prepared the polymer microspheres with mercapto groups by the polycondensations of 1,3-propanedithiol and 1,6-dibromohexane in the presence of $\mathrm{P}(\mathrm{S}-\mathrm{RAM})$ seed particles. Monodisperse particles were obtained in quantitative yields by using seed particles with hydrophilic surface. While using the hydrophobic P(S-NIPAM), all polymer was coagulated during the polycondensation. When an excess of dithiol was used in the polycondensation, the particles with high mercapto groups content were obtained and mercapto groups were localized near the surface.

Acknowledgment. This work was supported by a grant in aid for Scientific Research (11750755) from the Ministry of Education, Science, Sports and Culture, Japanese Government.

\section{REFERENCES}

1. a) I. Miraballes-Martinez, A. Martin-Molina, F. Galisteo-Gonzalez, and J. Forcada, J. Polym. Sci., Part A: Polym. Chem., 39, 2929 (2001).

b) I. Miraballes-Martinez and J. Forcada, J. Polym. Sci.,
Part A: Polym. Chem., 38, 4230 (2000).

c) K. Sakota and T. Okaya, J. Appl. Polymer Sci., 20, 1725 (1976).

2. H. Kitano, Z.-H. Sun, and N. Ise, Macromolecules, 16, 1306 (1983).

3. Y. Chonde, L.-J. Liu, and I. M. Krieger, J. Appl. Polym. Sci., 25, 2407 (1980).

4. a) S. Hosaka, Y. Murao, S. Masuko, and K. Miura, Immunol. Commun., 12, 509 (1983).

b) J. G. Park, J.-W. Kim, and K.-D. Suh, Colloid Polym. Sci., 279, 638 (2001).

5. S. Patai, "The Chemistry of the Thiol Groups", John Wiley \& Sons, Ltd., London, 1974.

6. T. Delair, C. Pichot, and B. Mandrand, Colloid Polym. Sci., 272, 72 (1994).

7. N. Kihara, C. Kanno, and T. Fukutomi, J. Polym. Sci., Part A: Polym. Chem., 35, 1443 (1997).

8. K. Yamaguchi, S. Watanabe, and S. Nakahama, Makromol. Chem., Rapid Commun., 10, 397 (1989).

9. S. Watanabe, S. Nakahama, and K. Yamaguchi, Makromol. Chem., 192, 1891 (1991).

10. S. Watanabe, O. Shishido, M. Murata, and Y. Masuda, Macromol. Rapid Commun., 19, 75 (1998).

11. S. Watanabe, S. Takano, O. Shishido, M. Murata, and Y. Masuda, Macromol. Chem. Phys., 200, 2577 (1999).

12. S. Watanabe, R. Ikeda, H. Kitagawa, M. Murata, and Y. Masuda, Macromol. Chem. Phys., 201, 896 (2000).

13. H. Kawaguchi, Y. Sugi, and Y. Ohtsuka, ACS Symp. Ser., 165, 145 (1981).

14. K. Yamashita, H. Saba, and K. Tsuda, J. Macromol. Sci.-Chem. A, 26, 1291 (1989).

15. Y. Imai, J. Macromol. Sci.—Chem. A, 15, 833 (1981).

16. S. Patai, "The Chemistry of the Thiol Groups", John Wiley \& Sons, Ltd., London, 1974, p 785. 